\title{
Topical tranexamic acid for the treatment of epistaxis in patients using antiplatelet agents
}

\author{
Mark Sanderson, $\mathrm{MD}^{*{ }^{\dagger}}$; James Powell, $\mathrm{MD}^{* \dagger}$; Eddy Lang, $\mathrm{MD}^{\ddagger \S}$
}

\section{ABSTRACT}

Clinical question: Does the addition of topical tranexamic acid to anterior nasal packing decrease bleeding in patients with epistaxis who are taking antiplatelet medications?

Article chosen: Zahed R, Jayazeri M, Naderi A, et al. Topical tranexamic acid compared with anterior nasal packing for treatment of epistaxis in patients taking antiplatelet drugs: randomized controlled trial. Acad Emerg Med 2018;25(3): 261-6.

Objectives: The primary outcome of this randomized controlled trial was the percentage of patients whose epistaxis had stopped at 10 minutes from the time of intervention. Secondary outcomes included the frequency of epistaxis recurrence at both 24 hours and 7 days, emergency department length of stay, and patient satisfaction.

\section{RÉSUMÉ}

Question Clinique: L'adjonction d'acide tranexamique topique au tamponnement nasal antérieur permet-elle de diminuer les hémorragies chez les patients prenant des inhibiteurs de l'agrégation plaquettaire et traités pour des épistaxis?

Article sélectionné: Zahed R, Mousavi Jazayeri MH, Naderi A, et al. Topical tranexamic acid compared with anterior nasal packing for treatment of epistaxis in patients taking antiplatelet drugs: randomized controlled trial. Acad Emerg Med 2018;25(3):261-6.

Objectifs: II s'agit d'un essai comparatif avec répartition aléatoire; l'objectif principal était le pourcentage de patients chez qui un arrêt de l'épistaxis a été observé 10 minutes après le début de l'intervention. Les objectifs secondaires comprenaient la fréquence des nouvelles épistaxis au bout de 24 heures et au bout de 7 jours, la durée de séjour au service des urgences et le degré de satisfaction des patients.

Keywords: Epistaxis, Tranexamic acid, Anti-platelet, Anterior Nasal Packing

\section{BACKGROUND}

Epistaxis is a common emergency department (ED) presentation with 450,000 presentations to American EDs yearly and a $60 \%$ lifetime risk of epistaxis in the general population. ${ }^{1,2}$ There are a number of commonly used interventions, including the application of topical vasoconstrictors, silver nitrate cautery or electrocautery for visible bleeding vessels, and anterior nasal packing (ANP) or application of commercially available inflatable devices. ${ }^{2}$

Aspirin (ASA) and clopidogrel are oral antiplatelet agents that are commonly prescribed for both the primary and secondary prevention of cardiovascular disease. The incidence of antiplatelet medication use in patients referred to otolaryngology (ENT) specialists for epistaxis management is as high as $37 \% .^{3}$

Tranexamic acid (TXA) is an antifibrinolytic that has been used in topical forms for the reduction of surgical bleeding ${ }^{4}$ and has been previously studied in epistaxis with mixed results. A recent systematic review of the literature on TXA use in epistaxis concluded that there is insufficient evidence to support the use of TXA for the management of epistaxis, though the authors felt that further research may prove beneficial. ${ }^{5}$

\section{POPULATION STUDIED}

A convenience sample was recruited consisting of patients presenting to the ED with new acute or recurrent epistaxis currently taking ASA, clopidogrel, or both. ${ }^{6}$ There were no age restrictions to enrolment. Patients were excluded if they could not provide consent or presented with 1) traumatic epistaxis, 2) current

From the *University of British Columbia, Vancouver, BC; †Kelowna General Hospital, Kelowna, BC; $\neq$ Emergency Medicine, Cumming School of Medicine, University of Calgary, Calgary, AB; and §Alberta Health Services, Edmonton, AB.

Correspondence to: Dr. Mark Sanderson, Emergency Department, Kelowna General Hospital, 2268 Pandosy St., Kelowna, BC V1Y 1T2; Email: mark.sanderson@alumni.ubc.ca 
anticoagulant use, 3) inherited bleeding or platelet disorders, 4) an international normalized ratio (INR) of $>1.5,5)$ vital signs consistent with shock, 6) a visible bleeding vessel, or 7) had a history of renal disease.

\section{STUDY DESIGN}

This study was a two-centre randomized, parallel group clinical trial. Patients with epistaxis not controlled with 20 minutes of external pressure were randomized in blocks of two, four, or six and stratified by site. Patients received either the intervention treatment of topically applied IV TXA on a $15-\mathrm{cm}$ cotton pledget or usual care consisting of ANP with tetracycline ointmentsoaked cotton for 3 days. Staff physicians or chief residents determined cessation of bleeding at 5-minute intervals by examining the oropharynx and in situ pledgets or packing for ongoing bleeding, and selfreported patient assessment of swallowed blood. ${ }^{6}$ Physicians, patients, and outcome assessors were not blind to the study interventions. Patients were followed by phone or in person at 24 hours, and 1 week following discharge from the ED.

\section{OUTCOME MEASURES}

The primary outcome was the proportion of patients with cessation of bleeding at 10 minutes from treatment initiation. Secondary outcomes included frequency of recurrent bleeding assessed by a phone call at 24 hours and 7 days, ED length of stay, and patient satisfaction measured by a numeric rating scale $(0-10)$.

\section{RESULTS}

During the study timeline, 384 patients were assessed for eligibility of which 260 met exclusion criteria and 124 were randomized: 62 allocated to ANP; 62 allocated to TXA. All patients received their allocated therapy, and none were lost to follow-up. Compared to patients randomized to ANP, The TXA group had a higher proportion of patients reporting a history of epistaxis ( $53 \%$ v. $21 \%$, respectively).

There was a significant difference between the proportion of patients whose bleeding had stopped at 10 minutes between the TXA group and the ANP group. Of patients receiving TXA, 73\% experienced cessation of bleeding by 10 minutes compared with $29 \%$ in the ANP group. Median time to cessation of bleeding was shorter, and rebleeding rates at 7 days after treatment were lower in the TXA group. Additionally, the proportion of patients with an ED length of stay $\leq 2$ hours was increased in the TXA group. There was no significant difference in the rates of rebleeding after 24 hours (Table 1). There were no complications.

\section{COMMENTARY}

This study builds on prior research by the authors on the use of TXA for the control of anterior epistaxis. ${ }^{7}$ There are some methodological concerns that affect the internal validity of this study, as discussed in the methodology section.

\section{Population}

Epistaxis severity was not graded or accounted for in any way, and the study randomization may have failed to properly account for this variable. In this study, the authors did not report the proportion of patients, if any, on dual antiplatelet therapy, and they did not define their population of interest with regards to the dosing or frequency of antiplatelet regimen, nor did they describe how recent the antiplatelet use must have been for patients to have been included in the study. These concerns may have compromised the randomization of patients in this study and thereby affected the internal validity.

Table 1. Effects of Tranexamic acid compared with Anterior nasal packing (selected results)

\begin{tabular}{lccc} 
& Tranexamic acid & Anterior nasal packing & Percentage difference (95\% Cl) \\
\hline Bleeding cessation $\leq 10$ minutes (\%) & 73 & 29 & $44(26-57)$ \\
Bleeding stop time (min) & $10(10-15)$ & $15(10-20)$ & 13 \\
Time to discharge $\leq 2$ hours (\%) & 97 & 10 & $84(71-91)$ \\
Rebleeding at 24 hours (\%) & 5 & 21 & $-5(-15-5)$ \\
Rebleeding at 1 week (\%) & 5 & $-16(-28-4)$
\end{tabular}




\section{Methodology}

Assessment for cessation of bleeding was not well characterized. In addition to the examination of the oropharynx and of the blood-soaked pledgets in situ, subjective patient assessment of ongoing swallowing of blood was used to determine whether bleeding abated. Due in part to perceived technical issues secondary to the physical characteristics of the intervention and the nature of the assessment techniques mentioned previously, neither the physicians nor the patients nor the outcome assessors were blinded in this study. It may have been possible to use ANP and TXA pledgets that were physically similar enough to blind the outcome assessors, thereby reducing the potential for bias in the assessment of bleeding cessation. Similarly, blinding the outcome assessors who followed via a telephone followup would have further improved the internal validity of this study.

\section{WILL THE RESULTS HELP ME CARE FOR MY PATIENTS?}

The use of ANP, as described in this study, is not a therapy typically used as first line for the rapid control of anterior epistaxis in Canadian EDs. A recent analysis of outcomes for anterior epistaxis in a Canadian tertiary care centre found that only $13 \%$ of patients underwent ANP with petroleum gel gauze packing, whereas 26\% were treated with a commercially available nasal tampon, and several more were treated with commercially available inflatable packing, or hemostatic agents. ${ }^{8}$ The described method of ANP may differ from what is common in Canadian EDs where proprietary inflatable devices, nasal tampons, or hemostatic agents are more common and vary from hospital to hospital. Furthermore, the described success rate of ANP of $29 \%$ seems low compared to similar interventions described in the literature with treatment success rates as high as $60 \%$ to $88 \%$ for ANP. ${ }^{3,8}$ Lastly, the selection of the primary end point (proportion with cessation within 10 minutes) is a key point on which the results of this paper hinge, and it is not clear from where this number originates.
Had a different time point been chosen, the results would have been very different, and we question whether the proportion of patients with cessation of bleeding at 10 minutes is a patient-centred and clinically relevant outcome.

\section{CONCLUSIONS}

The authors repeated and expanded upon their previous research by examining the effects of topical application of intravenous TXA for epistaxis in patients receiving ASA, clopidogrel, or both. The unblinded nature and lack of certain key patient demographics affect the overall validity of this study, and the lack of methodological clarity would make it difficult to reproduce. This topic requires further study before it can be recommended in Canadian EDs.

Competing interests: None declared.

\section{REFERENCES}

1. Pallin DJ, Chng Y, McKay MP, et al. Epidemiology of epistaxis in US emergency departments, 1992 to 2001. Ann Emerg Med 2005;46(1):77-81.

2. Gifford TO, Orlandi RR. Epistaxis. Otolaryngol Clin N Am 2008;41(3):525-36.

3. Smith J, Siddiq S, Dyer C, et al. Epistaxis in patients taking oral anticoagulant and antiplatelet medication: prospective cohort study. 7 Laryngol Otol 2011;125(1):38-42.

4. Ker K, Beecher D, Roberts I. Topical application of tranexamic acid for the reduction of bleeding. Cochrane Database Syst Rev 2013;7:CD010562.

5. Kamhieh Y, Fox H. Tranexamic acid in epistaxis: a systematic review. Clin Otolaryngol 2016;41(6):771-6.

6. Saeedi M. Emails sent to: Mark Sanderson. 05 February 2018.

7. Zahed R, Moharamzadeh P, AlizadehArasi S, et al. A new and rapid method for epistaxis treatment using injectable form of tranexamic acid topically: a randomized controlled trial. Am 7 Emerg Med 2013;31(9):1389-92.

8. Newton E, Lasso A, Petrcich W, Kilty SJ. An outcomes analysis of anterior epistaxis management in the emergency department. 7 Otolaryngol Head Neck Surg Le Fournal d'otorhino-laryngologie et de chirurgie cervico-faciale 2016;45(25):24. 